\title{
PHARMACOKINETICS OF TRAMADOL IN ENDOTOXEMIA USING AN ANIMAL MODEL
}

\author{
DANUTA SZKUTNIK-FIEDLER ${ }^{1 *}$, MONIKA BALCERKIEWICZ ${ }^{1}$, \\ TOMASZ GRABOWSKI ${ }^{2}$ and EDMUND GRZEŚKOWIAK ${ }^{1}$ \\ ${ }^{1}$ Department of Clinical Pharmacy and Biopharmacy, \\ Poznan University of Medical Sciences, Św. Marii Magdaleny 14, \\ 61-861 Poznań, Poland \\ ${ }^{2}$ Polpharma Biologics, Trzy Lipy 3, 80-172 Gdańsk, Poland
}

\begin{abstract}
Endotoxemia and systemic inflammation are known to affect many drugs' bioavailability, increasing toxicity or causing sub-therapeutic concentrations. Tramadol is a mild opioid commonly used to treat pain - whether acute or chronic. References available, however, provide no data on the pharmacokinetics of this opioid during systemic inflammation. Therefore, the aim of this pilot study was to examine the pharmacokinetics of tramadol after a single intravenous dose in experimentally induced endotoxemia - one of the well-established models of systemic inflammation. The study was conducted using 15 adults, healthy New Zealand white rabbits of both sexes. Endotoxemia was induced by single intravenous doses of Escherichia coli lipopolysaccharide (ECLPS): $5.0 \mu \mathrm{g} / \mathrm{kg}$ (group I) and $50.0 \mu \mathrm{g} / \mathrm{kg}$ (group II). It was shown that the plasma concentrations and $A U C_{0-\infty}$ values of tramadol in both groups of rabbits with endotoxemia were significantly higher $(p<0.05)$ than in the healthy animals. The ratios of the arithmetic means (group I/control and group II/control) for $C_{\max }$ and $A U C_{0-\infty}$ increased by 1.1, 0.8, 1.1., and 0.4-fold, respectively. Further studies are needed.
\end{abstract}

Keywords: endotoxemia, tramadol, rabbits, pharmacokinetics, pain, opioids

It has been shown that the pharmacokinetic processes of many drugs could be altered in systemic inflammation, both in humans and animals. These changes may be the cause of the higher bioavailability of drugs, resulting in an increased incidence of adverse events (1-6).

Inflammation may often be present in patients with chronic diseases with a pain component (7, 8 ) and in emergency situations in critically ill and postoperative patients (9). In all these cases, appropriate treatment of pain is essential, and any changes in drug pharmacokinetics may be one of the many factors that complicate pharmacotherapy. The ability to conduct clinical studies on the pharmacokinetics of drugs during inflammation might be quite limited. Therefore, those pharmacokinetic studies are often done using various animal models with the induction of experimental endotoxemia - one of the well-established models of systemic inflammation $(10,11)$. A lipopolysaccharide endotoxin (LPS), mainly isolated from Escherichia coli (ECLPS), is often used in these models (10).
The use of tramadol, especially in chronic pain, requires an awareness of its unique pharmacology (dual mechanism of action, inter-subject variability in the pharmacokinetics and pharmacodynamics depending on the cytochrome P450 changes and polymorphisms) to avoidance of adverse drug effects and ensure adequate analgesia throughout the treatment period (12). Tramadol pharmacokinetics has been well investigated, both in preclinical and clinical studies (13-17); however, to the best of our knowledge, there is no data on the pharmacokinetics of this opioid during inflammation. Due to the facts mentioned above, our study aimed to determine the pharmacokinetics of tramadol in experimentally induced endotoxemia using an animal model.

\section{EXPERIMENTAL}

\section{Chemicals and reagents}

Tramadol hydrochloride, $\mathrm{C}_{16} \mathrm{H}_{25} \mathrm{O}_{2} \mathrm{~N} \cdot \mathrm{HCl}$ (CAS: 27203-92-5), and internal standard (IS) phenacetin (CAS: 62-44-2) were supplied by Sigma-Aldrich Chemie GmbH (Munich, Germany). Tramadol

* Corresponding author: e-mail: dszkutnik@ump.edu.pl 
hydrochloride solution for injections (Tramal ${ }^{\circledR}$, $50 \mathrm{mg} / \mathrm{mL}$ ) was from STADA Arzneimittel AG, Bad Vilbel, Germany. Acetonitrile, ethyl acetate, n-hexane, methanol were HPLC grade from Merck (Darmstadt, Germany). Sodium hydroxide, monopotassium phosphate, anhydrous potassium hydrogen phosphate (analytical grade, pure for analysis) were purchased from Avantor Performance Materials Poland S.A. (Gliwice, Poland). Lipopolysaccharide from Escherichia coli (ECLPS) 0111:B4, lyophilized powder $10 \mathrm{mg}$, was purchased from Sigma-Aldrich Chemie $\mathrm{GmbH}$ (Munich, Germany).

\section{Animals}

Fifteen adults, New Zealand white rabbits of both sexes were used in the study. Before each experiment, food was withheld for $12 \mathrm{~h}$, but free access to fresh water was provided. The study was performed according to a protocol approved by the Local Ethical Committee (consent No. 15/2014), respecting the rules and guidelines concerning the care and use of laboratory animals (18).

\section{Experimental design}

All rabbits were divided into three groups ( $\mathrm{n}=5$ each): control group (mean body weight $4.3 \pm 0.9 \mathrm{~kg}$, healthy rabbits) - animals receiving a single intravenous dose of tramadol $(10 \mathrm{mg} / \mathrm{kg})$, study group I (mean body weight $5.0 \pm 0.2 \mathrm{~kg}$ ), and study group II (mean body weight $5.3 \pm 0.2 \mathrm{~kg}$ ) - animals receiving a single intravenous dose of tramadol $(10 \mathrm{mg} / \mathrm{kg}) 60$ minutes after induced endotoxemia. Endotoxemia was induced by a single intravenous administration of ECLPS at a dose of $5.0 \mu \mathrm{g} / \mathrm{kg}$ (group I) and $50.0 \mu \mathrm{g} / \mathrm{kg}$ (group II) dissolved in $0.5 \mathrm{~mL}$ pyrogen-free saline.

Doses of tramadol and ECLPS were based on previous studies $(19,20)$. Blood samples $(2.0 \mathrm{~mL})$ were obtained from a catheter remaining in the ear vein before $E$. coli administration (sample 0 ) and up to six hours after administration of tramadol. At the selected time-points $(1.0,2.0,4.0$, and $6.0 \mathrm{~h}$ after administration of tramadol), rectal temperature was measured. The experiments always started between 7.30 and 8.00 a.m.

\section{Analytical method}

Tramadol in rabbit plasma was analyzed by high-performance liquid chromatography using Waters 2695 Separations Module with an autosampler (integrated automatic sample manager up to 120 vials housed in an optional, temperature-controlled environment) with UV detection (Waters 2487 Dual 1
Absorbance Detector, wavelength $218 \mathrm{~nm}$ ) and serial flow path with pulse-free solvent delivery without the use of dampeners after a liquid-liquid extraction with a mixture of ethyl acetate-n-hexane (1: 4, v/v) (20). An analytical column XTerra RP-8, $250 \mathrm{~mm} \times$ $4.6 \mathrm{~mm}, 5 \mu \mathrm{m}$ (Waters Corporation ${ }^{\circledR}$, Milford, MA, USA), and the mobile phase consisting of acetonitrile and $0.01 \mathrm{M}$ phosphate buffer (20: 80, v/v) with a flow rate of $1.0 \mathrm{~mL} / \mathrm{min}$ were used. The volume of each injection was $60 \mathrm{~L}$. Retention times for tramadol and internal standards were 7.5 and $15.0 \mathrm{~min}$ utes, respectively.

The method was validated according to published European Medicines Agency guidelines (21). Data collection and processing were carried out using Empower ${ }^{\mathrm{TM}}$ Pro software, v. 1154 (Waters Corporation $^{\circledR}$, Milford, MA, USA). The calibration for tramadol was linear in the tramadol concentration range of 50-5000 $\mathrm{ng} / \mathrm{mL}(\mathrm{r}=0.998)$. Withinand between-run precision and accuracy were determined for the following tramadol concentrations: 50 , 150,2500 , and $4000 \mathrm{ng} / \mathrm{mL}$. For all of the analyzed concentrations, within- and between-run precision was less than $9 \%$ and $14 \%$, respectively. The accuracy (percent of the nominal value) was from $94.5 \%$ to $106.2 \%$ (within-run) and from $95.6 \%$ to $103.3 \%$ (between-run).

\section{Pharmacokinetic analysis}

Tramadol pharmacokinetic parameters: elimination rate constant $\left(k_{e l}\right)$, elimination half-life $\left(t_{1 / 2 k e l}\right)$, area under the plasma curve from zero to the last measurable concentration $\left(A U C_{0-t}\right)$, area under the plasma curve from zero to infinity $\left(A U C_{0-\infty}\right)$, total body clearance $(\mathrm{Cl} / \mathrm{F})$, apparent volume of distribution $\left(V_{D}\right)$ and mean residence time $(M R T)$ were calculated by the noncompartmental methods using validated PhoenixTM 7.0 WinNonlin ${ }^{\circledR}$ software (Certara L.P., Princeton, NJ, USA). The maximum tramadol plasma concentration $\left(C_{\max }\right)$ was determined directly from the concentration $v s$. time curve.

\section{Statistical analysis}

For statistical analysis, the STATA ${ }^{\circledR}$ (StataCorp LP, Texas, USA) program was used. Pharmacokinetic parameters of tramadol were presented as the arithmetic mean \pm SD (standard deviation). The ShapiroWilk test was used to determine if the pharmacokinetic parameters and plasma concentrations of tramadol (at each individual time point in all three groups) followed the normal distribution. Intergroup differences in all of the pharmacokinetic parameters and plasma concentrations (except concentrations of 
tramadol in group II at the time point of $10.0 \mathrm{~min}$ ) were normally distributed and were analyzed using a one-way analysis of variance (ANOVA fixed-effects models). The difference with significant deviation from normality was tested with the Kruskal-Wallis test. Tukey test was applied for post hoc comparisons among all the groups. Statistical significance was set at $p<0.05$.

\section{RESULTS}

The mean plasma concentration-time profiles of tramadol in healthy (control group) and endotoxemic rabbits (group I and group II) are presented in Figure 1. Comparing the mean plasma concentrations of tramadol at each time point for each group, it was shown that in both groups of rabbits with endotoxemia, the mean plasma concentrations of tramadol, especially at the first time points, were statistically higher $(p<0.05)$ compared to the control group. Comparing group I with group II, the mean tramadol plasma concentrations were comparable, except at $45.0 \mathrm{~min}$ after administration of tramadol $(p<0.05)$, when higher values were observed in group I (Figure 1).

Comparing the healthy and endotoxemic rabbits, statistically significant differences $(p<0.05)$ for the following pharmacokinetic parameters of tramadol: $C_{\text {max }}, A U C_{0-t}$ and $A U C_{0-\infty}$ were observed. The arithmetic mean of the maximum plasma concentration of tramadol in both groups of rabbits with induced endotoxemia increased by $112 \%$ (group I) and $82 \%$ (group II) when compared with the control rabbits (the ratios: group I/control and group II/control were increased by 1.1 - and 0.8 -fold, respectively) (Table 1, Figure 1). Confidence interval values $(90 \% \mathrm{CI})$ for the difference between means: control-group I and control-group II were

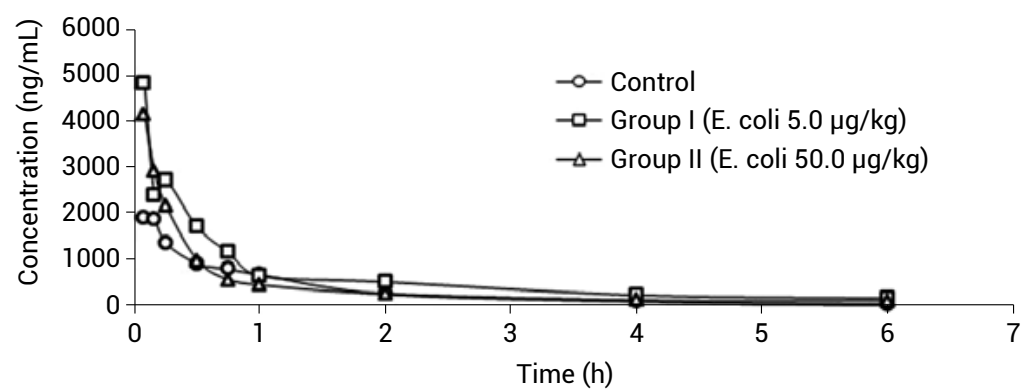

Figure 1. Plasma concentration-time profiles of tramadol $(10 \mathrm{mg} / \mathrm{kg})$ after intravenous administration in healthy (Control) and endotoxemic (Group I and Group II) rabbits.

Notes: $p<0.05$ between the groups were observed at the following time points (analysis of variance ANOVA):

Group I vs. Control: $5.0 \mathrm{~min}(p=0.038), 15.0 \mathrm{~min}(p=0.028), 2.0 \mathrm{~h}(p=0.036), 4.0 \mathrm{~h}(p=0.027)$, and $6.0 \mathrm{~h}(p=0.018)$;

Group II vs. Control: $5.0 \mathrm{~min}(p=0.006), 10.0 \mathrm{~min}(p=0.015), 15.0 \mathrm{~min}(p=0.025)$, and $6.0 \mathrm{~h}(p=0.016)$;

Group I vs. Group II: $45.0 \min (p=0.033)$.

Table 1. The pharmacokinetic parameters of tramadol after single intravenous administration $(10 \mathrm{mg} / \mathrm{kg})$ in healthy (Control) and endotoxemic (Group I and Group II) rabbits.

\begin{tabular}{|c|c|c|c|}
\hline \multirow{2}{*}{ Parameter } & $\begin{array}{c}\text { Group I }(\mathrm{n}=5) \\
(\text { E. coli } 5.0 \mu \mathrm{g} / \mathrm{kg})\end{array}$ & $\begin{array}{c}\text { Group II }(\mathrm{n}=5) \\
\text { (E. coli } 50.0 \mu \mathrm{g} / \mathrm{kg})\end{array}$ & \multirow{2}{*|}{ Control $(\mathrm{n}=5)$} \\
\cline { 2 - 4 } & \multicolumn{3}{|c|}{ Arithmetic mean $\pm \mathrm{SD}$} \\
\hline$C_{\max }(\mathrm{ng} / \mathrm{mL})$ & $4828 \pm 2282^{*}$ & $4131 \pm 958^{*}$ & $2268 \pm 560$ \\
\hline$A U C_{0-t}(\mathrm{ng} \times \mathrm{h} / \mathrm{mL})$ & $4084 \pm 1839^{*}$ & $2652 \pm 601$ & $2132 \pm 480$ \\
\hline$A U C_{0-\infty}(\mathrm{ng} \times \mathrm{h} / \mathrm{mL})$ & $4632 \pm 2139^{*}$ & $2991 \pm 624^{*}$ & $0.47 \pm 0.15$ \\
\hline$k_{e l}(1 / \mathrm{h})$ & $0.35 \pm 0.19$ & $0.35 \pm 0.20$ & $1.62 \pm 0.52$ \\
\hline$t_{1 / 2 k e l}(\mathrm{~h})$ & $2.81 \pm 2.02$ & $2.51 \pm 1.24$ & $1.49 \pm 0.27$ \\
\hline$M R T(\mathrm{~h})$ & $2.22 \pm 0.94$ & $2.11 \pm 0.72$ & $20.71 \pm 4.46$ \\
\hline$C l / F(\mathrm{~L} / \mathrm{h})$ & $14.74 \pm 6.96$ & $21.22 \pm 6.10$ & $25.88 \pm 6.99$ \\
\hline$V_{D}(\mathrm{~L})$ & $20.26 \pm 10.42$ & $25.23 \pm 8.85$ & \\
\hline
\end{tabular}

Abbreviations: $\mathrm{SD}$ - standard deviation; $C_{\max }$ - maximum plasma concentration; $A U C_{0-t}$ - area under the plasma curve from zero to the last measurable concentration; $A U C_{0-\infty}$ - area under the plasma curve from zero to infinity;

$k_{e}$ - elimination rate constant; $t_{t, k e l}$ - elimination half-life; $M R T$ - mean residence time; $C l / F$ - total body clearance;

$V_{D}$ - apparent volume of distribution;

Notes: $* p<0.05$ vs. Control (analysis of variance ANOVA) 
$831 ; 4288$ and $1046 ; 2679$, respectively. For the area under the plasma curves from zero to the last measurable concentration $\left(A U C_{0-t}\right)$ and from zero to infinity $\left(A U C_{0-\infty}\right)$, statistically higher values $(p<0.05)$ in endotoxemia were observed compared to the control (for group I, the arithmetic mean of $A U C_{0-t}$ increased by $91 \%$ (90\% CI 553; 3350), for the group I and II the $A U C_{0-\infty}$ increased by $109 \%(90 \%$ CI 806 ; $4033)$ and $35 \%(90 \%$ CI 196; 1361), respectively) (Table 1). For other pharmacokinetic parameters, there were no statistically significant differences. Comparing group I with group II, there were no differences for all analyzed pharmacokinetic parameters (Table 1).

\section{DISCUSSION}

In this study, the pharmacokinetics of tramadol in rabbits with experimentally induced endotoxemia, which is one of the well-established models of inflammation, was investigated. Two levels of endotoxemia were induced by a single administration of $5 \mu \mathrm{g} / \mathrm{kg}$ and $50 \mu \mathrm{g} / \mathrm{kg}$ of ECLPS dissolved in $0.5 \mathrm{~mL}$ pyrogen-free saline one hour before tramadol administration. The study design (doses and timing of ECLPS and tramadol administration) was established based on previous studies $(19,22)$.

Tramadol plasma concentrations were determined by the HPLC method, which was characterized by good linearity in the studied concentration range $50-5000 \mathrm{ng} / \mathrm{mL}(\mathrm{r}=0.998)$. The analysis of quality-control samples at concentrations of tramadol of 50, 150, 2500, and $4000 \mathrm{ng} / \mathrm{mL}$ indicates a good within- and between-run accuracy and precision.

We have shown that the maximum plasma concentrations of tramadol and the AUC values were significantly higher in rabbits with two stages of endotoxemia compared to the healthy animals. The ratios of the arithmetic means (group I/control and group II/control) for $C_{\max }$ and $A U C_{0-\infty}$ increased by $1.1,0.8,1.1$, and 0.4 -fold, respectively. Comparing the $A U C_{0-t}$ values statistically significant difference was observed only for group I (the ratio group I/control was 1.9 ). Comparing both groups of rabbits with endotoxemia, no differences in the plasma concentrations and all of the pharmacokinetic parameters of tramadol were observed (Table 1, Figure 1).

It is known that systemic inflammation is associated with a decrease in hepatic expression and/or activities of cytochrome P450 (CYP) enzymes $(1,4)$. As demonstrated, ECLPS can also downregulate the expression or activities of hepatic, intestinal, and renal drug-metabolizing enzymes in some animal species, including rabbits (23). Tramadol is metabolized via the cytochrome P450 CYP2D6 enzymes to the active M1 metabolite ( $O$-desmethyltramadol), both in humans and rabbits. Therefore, the observed higher plasma concentrations of tramadol in rabbits with endotoxemia may be the consequence of its lower metabolism $(12,13)$. In future studies, plasma levels of the active metabolite $O$-desmethyltramadol should also be measured. Apparently, tramadol is metabolized more rapidly in animals than in men (13).

It is interesting that the observed significant changes in the pharmacokinetics of tramadol have already occurred after a low-dose ECLPS induced endotoxemia (group I) and were similar to the changes noted after administration of a dose of ECLPS ten times higher (group II). No correlation has been demonstrated between the changes in the pharmacokinetics of tramadol and the severity of endotoxemia. Other pharmacokinetic parameters of tramadol like: $\left.\mathrm{kel}, \mathrm{t}^{1 / 2} \mathrm{kel}\right), \mathrm{MRT}$, and $\mathrm{Cl} / \mathrm{F} \mathrm{did}$ not differ significantly between endotoxemic and healthy animals (Table 1). However, the obtained values may indicate a slightly lower elimination of tramadol in rabbits with endotoxemia due to: lower body clearance (only in group I with low-dose endotoxemia), and lower elimination rate (both groups of endotoxemia), and higher biological half-life and mean residence time (both groups of endotoxemia). A tendency to lower the elimination of tramadol in animals with endotoxemia may also be the cause of the increased plasma concentrations and AUC values of this opioid observed in our study. Although, due to a small group of animals, it could be a random variation.

The distribution of drugs during the inflammatory states can vary considerably; both a decrease $(19,26)$ or an increase (3) were observed. Increased values have been found mostly for hydrophilic drugs due to higher extravascular volume (3). In our study, the apparent volume of distribution of tramadol in rabbits with low-dose endotoxemia (group I) was slightly lower $(p>0.05)$ compared to the healthy animals. It could have been the result of developing inflammation and thus compromised tissue perfusion $(19,26)$. However, in rabbits with high-dose endotoxemia (group II), this parameter was comparable to the healthy rabbits. Similar trends in the pharmacokinetics of drugs during endotoxemia in animals have been observed for morphine (19) and ketamine (24). More significant changes in the pharmacokinetics were noted 
in low-dose (group I) compared to high-dose endotoxemia (group II).

In our study, differences in body weight of rabbits from control (mean body weight $4.3 \pm 0.9 \mathrm{~kg}$ ) and study groups (group I - mean body weight $5.0 \pm 0.2 \mathrm{~kg}$, group II - mean body weight $5.3 \pm 0.2 \mathrm{~kg}$ ) were observed. Standard deviation values for the control group are also higher than for the study groups. However, both tramadol and ECLPS were administered to rabbits at doses based on their body weight, and therefore the obtained tramadol plasma concentrations and pharmacokinetic parameters should not be affected.

The results of animal $(3,19,23)$ and human $(25,26)$ studies indicate that variations in the pharmacokinetics of drugs used in endotoxemia may be remarkably different. This may be due to the properties of the drug itself, the dose and type of lipopolysaccharide and the characteristics of the animal species used in animal models, and the severity of infection and inflammatory in the patients, among other factors (3).

\section{Limitations of the study}

Due to the physiological differences between rabbits and humans, like changes in oncotic pressure, tissue perfusion, and liver function (27), our results cannot be directly extrapolated to patients. However, this animal model of experimentally induced endotoxemia can provide basic information about the changes in the pharmacokinetics of tramadol $(10,11)$. An important limitation was also the fact that the plasma concentrations and pharmacokinetic parameters of the active metabolite of tramadol $O$-desmethyltramadol were not determined.

\section{CONCLUSION}

We observed changes in the pharmacokinetics of tramadol in rabbits with endotoxemia compared to the healthy animals. This justifies further clinical studies on modifying the dosing regimens of this opioid during systemic inflammation.

\section{CONFLICT OF INTEREST}

The authors declare no conflicts of interest.

\section{REFERENCES}

1. Renton K.W.: Expert Opin. Drug Metab. Toxicol. 1, 629 (2005).
2. Schmith V.D., Foss J.F.: Clin. Pharmacol. Ther. 83, 809 (2008).

3. Yang K.H., Lee M.G.: Arch. Pharm. Res. 31, 1073 (2008).

4. Morgan E.T.: Clin. Pharmacol. Ther. 85, 434 (2009).

5. Cressman A.M., Petrovic V., Piquette-Miller M.: Expert Rev. Clin. Pharmacol. 5, 69 (2012).

6. Coskun D, Corum O, Yazar E.: J. Vet. Pharmacol. Ther. 43, 288 (2020).

7. Els C., Jackson T.D., Kunyk D., Lappi V.G., Sonnenberg B., Haqtvedt R., et al.: Cochrane Database Syst. Rev. 10, CD012509 (2017).

8. Raffaeli W., Arnaudo E.: J. Pain Res. 10, 2003 (2017).

9. Reardon D.P., Anger K.E., Szumita P.M.: Am. J. Health Syst. Pharm. 72, 1531 (2015).

10. Burkovskiy I., Zhou J., Lehmann Ch.: ABB 4, 424 (2013).

11. Popov D., Pavlov G.: TJS 1, 13 (2013).

12. Ahmadimanesh M., Naeini M.B., Rouini M.R., Shadnia S., Ghazi-Khansari M.: Drug Metab. Pers. Ther. 2020, 20190021; Epub ahead of print (2020).

13. Gong L., Stamer U.M., Tzvetkov M.V., Altman R.B., Klein T.E.: Pharmacogenet. Genomics 24, 374 (2014).

14. Miotto K., Cho A.K., Khalil M.A., Blanco K., Sasaki J.D., Rawson R.: Anesth. Analg. 124, 44 (2017).

15. Bailey R.S., Sheldon J.D., Allender M.C., Papich M.G., Chinnadurai S.K.: J. Vet. Pharmacol. Ther. 42, 380 (2019).

16. Lee J., Yoo H.D., Bae J.W., Lee S., Shin K.H.: Drug Des. Devel. Ther. 13, 1751 (2019).

17. Siepsiak-Połom M., Szałek E., Porażka J., Karbownik A., Grabowski T., et al.: Eur. Rev. Med. Pharmacol. Sci. 23, 4044 (2019).

18. Directive 2010/63/EU of the European Parliament and of the Council of 22 September 2010 on the protection of animals used for scientific purposes. OJEU (20.10.2010) L 276/33-L 276/79. Available at: Directive 2010/63/EU of the European Parliament and of the Council of 22 September 2010 on the protection of animals used for scientific purposes text with EEA relevance (europa.eu) (accessed on 01.02.2021).

19. Szkutnik-Fiedler D., Billert H., Grabowski T., Lisiecka J., Michalak M., et al.: Pain Med. 17, 1407 (2016).

20. Szkutnik-Fiedler D., Grześkowiak E., Madziała J.: Farm. Współcz. 6, 3 (2013) (in Polish).

21. European Medicines Agency. Guideline on Bioanalytical Method Validation (21 July 
2011) Committee for Medicinal Products for Human Use (CHMP) EMEA/CHMP/ EWP/192217/2009 Rev. 1 Corr.2**, Available at: http://www.ema.europa.eu/docs/en_GB/ document_library/Scientific_guideline/2011/08/ WC500109686.pdf (accessed on 01.02.2021).

22. Elmas M., Yazar E., Uney K., Er Karabacak A.: J. Vet. Med. A Physiol. Pathol. Clin. Med. 53, 410 (2006).

23. Saitoh T., Kokue E., Shimoda M.: J. Vet. Pharmacol. Ther. 22, 87 (1999).
24. Veilleux-Lemieux D., Beaudry F., Hélie P.: Vet. Med. 3, 99 (2012).

25. Mahmoudi L., Mohammadpour A.H., Ahmadi A., Niknam R., Mojtahedzadeh M.: Eur. Rev. Med. Pharmacol. Sci. 17, 285 (2013).

26. Shimamoto Y., Fukuda T., Tanaka K., Komori K., Sadamitsu S.: Intensive Care Med. 39, 1247 (2013).

27. De Paepe P., Belpaire F.M., Buylaert W.A.: Clin. Pharmacokinet. 41, 1135 (2002). 